\title{
Nilai Laju Pelarutan Batu Gamping Pada Mataair Sumber Agung Di Kecamatan Sumbermanjing Wetan Kabupaten Malang
}

\author{
Nelya Eka Susanti ${ }^{1}$, Ika Meviana ${ }^{1}$ \\ ${ }^{1}$ Program Studi Pendidikan Geografi, Universitas Kanjuruhan Malang, Malang 65148, Indonesia \\ Email:*nelyaeka@unikama.ac.id, meviana@unikama.ac.id
}

Dikirim : 18 Maret 2019

Diterima: 30 Maret 2019

\begin{abstract}
Abstrak: Kabupaten Malang. Bagian selatan Kabupaten Malang merupakan perbukitan kapur (Karst Malang Selatan) pada ketinggian 0-650 mdpl. Bagian utara merupakan daerah lereng Arjuno-Tengger yang berada pada ketinggian 600-2700 mdpl, bagian timur merupakan daerah lereng Tengger-Semeru, membujur dari utara ke selatan pada ketinggian 500-3600 mdpl, dan bagian barat merupakan daerah lereng Kawi-Arjuno, terdapat pada ketinggian 500-3.300 mdpl. Tujuan penelitian ini menganalisis variasi temporal laju pelarutan batugamping pada mataair sampel dikawasan Karst Malang Selatan. Jenis penelitian ini adalah survei. Populasi penelitian ini adalah seluruh mataair yang berada pada kawasan Karst Malang Selatan, sedangkan sampel penelitian ini adalah mataair yang terletak di Kecamatan Sumbermanjing Wetan. Pengambilan data lapangan untuk variabilitas spasial dan temporal pada mataair mengacu pada periode sampling mingguan yang dilakukan dengan interval waktu dua minggu selama 6 bulan. Hal tersebut dilakukan untuk mengetahui fluktuasi dan perubahan material yang terlarut. Data hasil pengukuran dilakukan analisis variabilitas $\mathrm{HCO}_{3-}$ dan analisis laju pelarutan sehingga dapat diketahui beberapa aspek yang berpengaruh terhadap hasil penelitian. Berdasarkan hasil penelitian, diperoleh nilai konsentrasi $\mathrm{HCO}_{3}^{-}$terlarut tahunan tertinggi yang terdapat pada mataair Sumber Agung terjadi pada saat musim kemarau, sebesar 609,71 mg/l. Sedangkan konsentrasi $\mathrm{HCO}_{3}$ - terlarut terendah yang terdapat pada mataair Sumber Agung terjadi pada saat musim penghujan, yakni sebesar $531,72 \mathrm{mg} / \mathrm{l}$.
\end{abstract}

Kata kunci: karst, mataair, laju pelarutan

\section{Pendahuluan}

Kawasan karst di permukaan bumi mencakup 22 milyar $\mathrm{km}^{2}$. Indonesia sendiri diperkirakan memiliki wilayah karst seluas $\pm 14.000 .000 \mathrm{~km}^{2}$. Dalam tulisannya, Haryono (2008) menyebutkan bahwa melalui proses denudasi (pelarutan) pada kawasan karst di Indonesia, jumlah karbondioksida yang dapat terserap dari proses tersebut mencapai 13,482 $\mathrm{Gg} \mathrm{CO}_{2} /$ tahun. Pada tulisannya tersebut, Haryono (2008) menggunakan asumsi kehilangan 1 ton $\mathrm{CaCO}_{3}$ pada batuan karbonat akan menyerap $120 \mathrm{~kg}$ karbondioksida.

Kabupaten Malang merupakan daerah dataran tinggi yang dikelilingi oleh beberapa gunung dan memiliki daerah lembah pada ketinggian 250-500 meter di atas permukaan laut (mdpl) yang terletak di bagian tengah wilayah Kabupaten Malang. Bagian selatan Kabupaten Malang merupakan daerah perbukitan kapur (Karst Malang Selatan) pada ketinggian 0-650 mdpl, bagian utara merupakan daerah lereng Arjuno-Tengger berada pada ketinggian 600$2700 \mathrm{mdpl}$, bagian timur merupakan daerah lereng Tengger-Semeru, membujur dari utara ke selatan pada ketinggian 500-3600 mdpl, dan bagian barat merupakan daerah lereng KawiArjuno, terdapat pada ketinggian 500-3.300 mdpl.

Kawasan karst berbeda dengan kawasan lain, di mana proses eksogen dan endogen menciptakan suatu bentukan khas yang disebut topografi karst. Di kawasan karst, proses eksogen memiliki pengaruh lebih besar dalam pembentukan topografi daripada proses endogen. Proses eksogen yang berperan membentuk topografi karst adalah pelarutan, pengikisan oleh air, dan pengendapan. Pelarutan merupakan proses yang dominan ditemui di 
akuifer karst, karena adanya interaksi unsur karbon dioksida dalam air hujan dengan batuan karbonat yang menjadikan pelarutan semakin intensif.

Konsep proses pelarutan dari waktu ke waktu terus mengalami perkembangan seperti berikut: Pada awal abad ke-19 konsep tentang proses pelarutan batuan karbonat dianggap hanya terjadi pada tanah yang berada beberapa meter di atas batuan induk (soilzone); berkembang pada pertengahan abad ke-19 bahwa pelarutan batuan karbonat banyak terjadi pada 10 meter di bawah permukaan tanah atau zona epikarst (subcutaneous zone); diasumsikan lagi bahwa pelarutan terjadi di sepanjang aliran yang melalui batuan karbonat.

Ketiga asumsi di atas dianggap sebagai dasar dalam penelitian terkini yang menunjukkan bahwa pelarutan selalu terjadi pada air hujan yang mengalir melalui akuifer karbonat baik pada zona jenuh maupun pada zona tidak jenuh (Cvijik, 2006). Berbagai proses yang terbentuk dari hasil transformasi hujan dan imbuhan air tanah di kawasan karst akan dikeluarkan melalui outlet berupa mataair ataupun sungai permukaan. Mataair ini terjadi karena perbedaan elevasi muka airtanah (hydraulichead) pada akuifer dan elevasi permukaan tanah di mana mataair tersebut muncul (Kresic, 2010).

Pelarutan merupakan proses yang sangat penting pada daerah karst, yang mengontrol terbentuk dan berkembangnya topografi karst. Salah satu faktor yang mengontrol terbentuknya bentuklahan karst adalah adanya batuan mudah larut yang tersingkap pada ketinggian yang memungkinkan drainase air secara vertikal. Variabel yang menentukan proses pelarutan adalah kemurnian batuan karbonat, keasaman $(\mathrm{pH})$ air media pelarut, temperatur, dan kandungan $\mathrm{CO}_{2}$.

Proses pelarutan menyebabkan terjadinya perkembangan bentuk lahan karst, yaitu semakin besar laju pelarutan, maka semakin berkembang bentuklahan karst sehingga pada akhirnya bentukan karst akan hilang dan menyisakan batuan dasarnya. Laju pelarutan yang tinggi juga menunjukkan tingkat denudasi yang tinggi pada daerah tersebut. Tingginya pelarutan di kawasan Karst Malang Selatan dapat terlihat dari tingginya kandungan $\mathrm{HCO}_{3}-$ yang terlarut dalam mataair. Sacara umum morfologi Karst Malang Selatan tidak sebagus morfologi karst lainnya, apabila dibandingkan dengan morfologi Karst Gunung Sewu yang masih ideal, kenampakan bentukan karst di kawasan Karst Malang Selatan sudah banyak yang hilang, hal ini menandakan bahwa tingkat pelarutan yang terjadi di Kawasan Karst Malang Selatan cukup tinggi.

Melihat kondisi tersebut sangat menarik apabila dilakukan penelitian mengenai laju pelarutan batugamping pada kawasan Karst Malang Selatan tepatnya di Kecamatan Sumbermanjing Wetan secara temporal. Kecamatan Sumbermanjing Wetan adalah sebuah kecamatan di bagian selatan Kabupaten Malang yang keseluruhan wilayahnya masuk kedalam kawasan Karst Malang Selatan. Penelitian laju pelarutan secara temporal dilakukan dengan analisa alkalinitas mataair karst yang berada pada Kecamatan Sumbermanjing Wetan.

Tujuan dari penelitian ini adalah menganalisis variasi temporal laju pelarutan batugamping pada mataair sampel di daerah penelitian.

\section{Metode Penelitian}

Jenis penelitian ini adalah penelitian survei yang dilakukan di kawasan perbukitan Karst Malang Selatan. Penentuan sampel dalam penelitian ini menggunakan metode Purposive Sampling. Purposive Sampling adalah pengambilan sampel berdasarkan pada maksud dan tujuan penelitian, yang menjadi dasar dalam penentuan sampel adalah aspek spasial dan temporal. Populasi dalam penelitian ini adalah seluruh mataair yang berada pada kawasanKarst Malang Selatan, sedangkan sampel dalam penelitian ini adalah mataair yang terletak di Kecamatan Sumbermanjing Wetan. 


\section{Pengumpulan Data}

Pengambilan data lapangan untuk variabilitas spasial dan temporal pada mataair mengacu pada periode sampling mingguan yang dilakukan dengan interval waktu dua minggu selama 6 bulan agar data yang diperoleh akurat dan konstan. Hal ini dilakukan untuk mengetahui fluktuasi dan perubahan material yang terlarut. Selain itu pada musim penghujan kondisi mataair (warna, kekeruhan) di daerah penelitian memiliki perubahan yang tidak terlalu signifikan.

Data yang dikumpulkan dalam penelitian adalah data primer dan sekunder. Data primer diperoleh dari pengamatan, pengukuran lapangan, dan pendokumentasian, sedangkan untuk data sekunder diperoleh dari Badan Informasi Geospasial (BIG), Badan Pusat Statistik (BPS), Badan Meteorologi Klimatologi dan Geofisika (BMKG), serta penelitian terdahulu mengenai karakteristik mataair dan juga deskripsi wilayah di daerah penelitian. Data primer yang dikumpulkan dalam penelitian ini meliputi: (1) kandungan fisik (suhu, warna, dan kekeruhan), (2) kandungan kimia air ( $\mathrm{pH}$, dan $\left.\mathrm{HCO}_{3^{-}}\right)$. Data sekunder yang dikumpulkan meliputi: (1) Peta Rupa Bumi Indonesia (RBI) skala 1 : 25.000, (2) Peta Geologi Lembar Turen Skala 1 : 100.000, (3) Citra satelit, dan (4) sumber data instansional serta penelitian sebelumnya.

\section{Analisis Data}

Teknik analisis data dilakukan untuk mengetahui nilai $\mathrm{HCO}_{3-\text {. }}$ Data hasil pengukuran perlu diolah dan dilakukan analisis variabilitas $\mathrm{HCO}_{3}$ - dan analisis laju pelarutan sehingga dapat diketahui beberapa aspek yang berpengaruh terhadap hasil penelitian. Analisis variabilitas nilai $\mathrm{HCO}_{3}$ - terlarut diukur secara langsung di lapangan. Besar kecilnya $\mathrm{HCO}_{3}-$ yang terlarut pada suatu mataair dipengaruhi oleh $\mathrm{CO}_{2}$ yang terkandung dalam air hujan (presipitasi). Nilai kandungan $\mathrm{HCO}_{3}$ - yang diperoleh akan ditampilkan dalam bentuk grafik dan tabel.

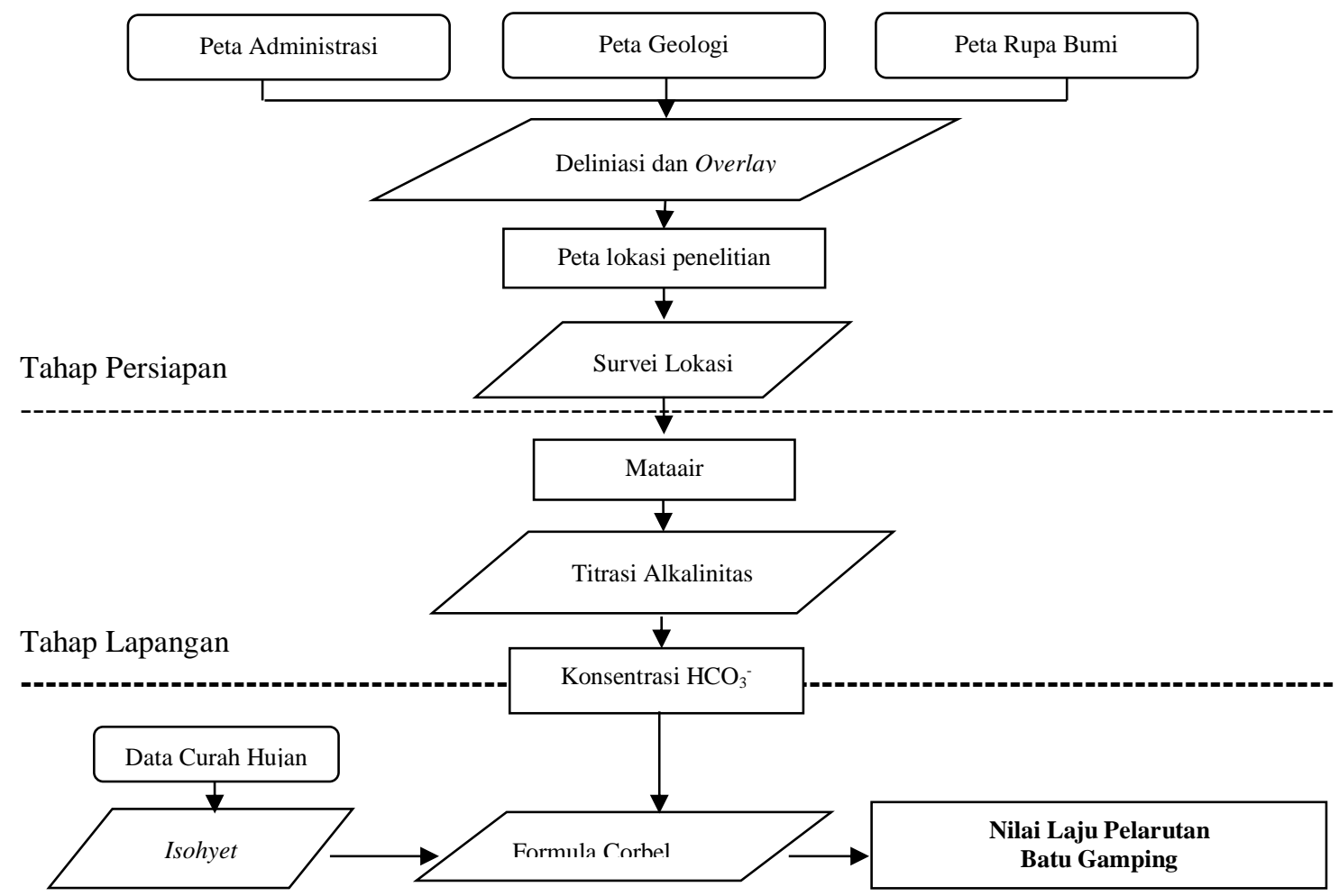




\section{Hasil Penelitian}

\section{Gambar 1. Diagram Alir Penelitian (Peneliti, 2018)}

Mataair Sumber Agung terletak di Desa Sumber Agung, Kecamatan Sumbermanjing Wetan, Kabupaten Malang. Secara geografis letak mataair ini berada pada koordinat X: 0686590 dan Y: 9082815.
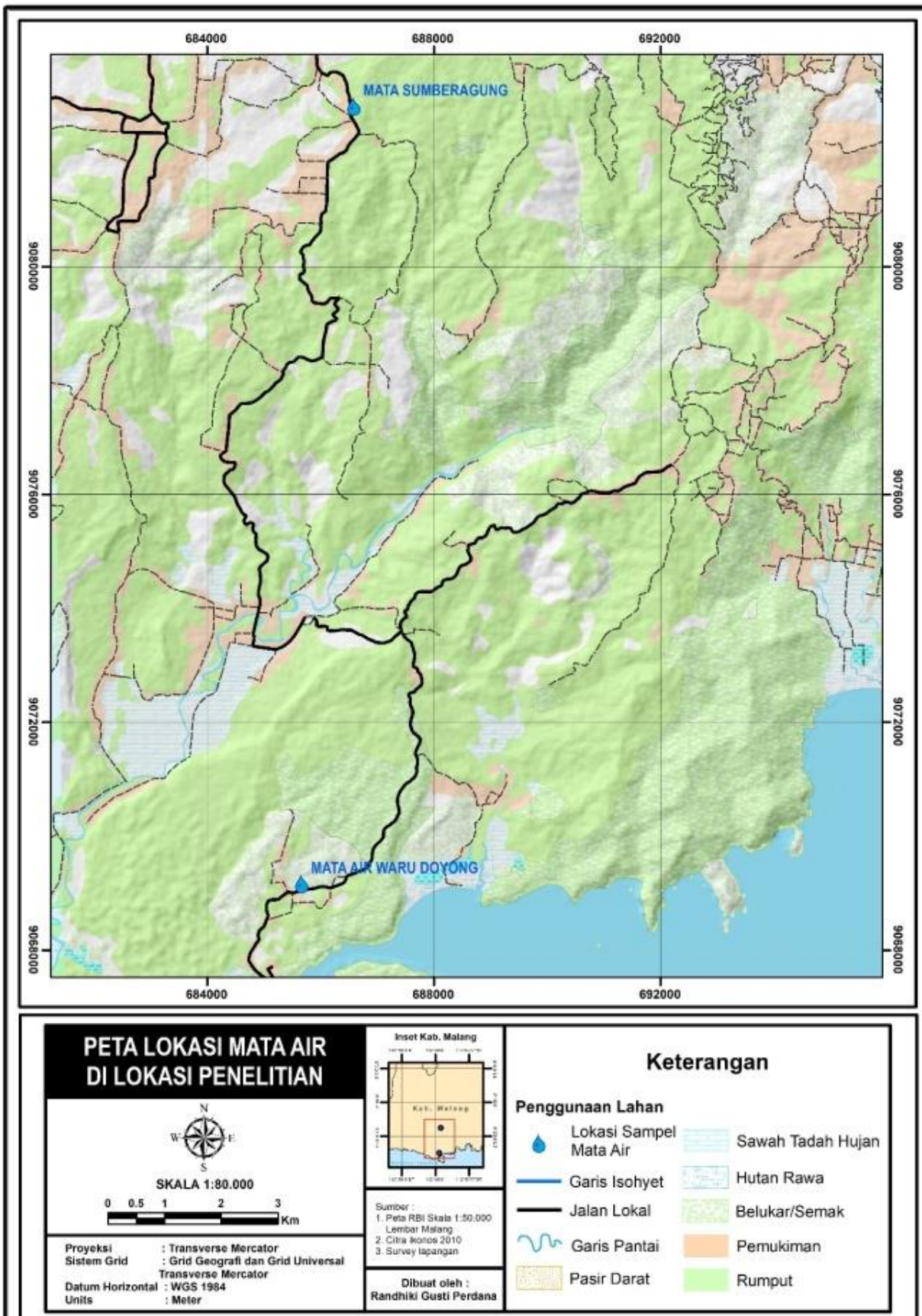

Gambar 2. Peta Lokasi Penelitian 


\section{Karakteristik lokasi penelitian}

\section{Kondisi geologi}

Secara geologi, Malang Selatan tersusun atas endapan gunung api, batuan terobosan dan batuan sedimen. Dari tua ke muda batuan penyusunnya antara lain: Formasi Mandalika, Formasi Wuni, Formasi Nampol, Formasi Wonosari, Batuan Terobosan (Intrusi) yang terdiri dari Diorit Kuarsa, Granodiorit, dan Dasit.

\section{Kondisi geomorfologi}

Daerah penelitian secara umum, sebagian besar terdiri dari pegunungan dan bukit-bukit landai yang berkelompok dengan bentuk memanjang atau hampir membulat dan mempunyai arah penyebaran relatif utara selatan. Ketinggian daerah penelitian antara 12,5 meter hingga 550 meter diatas permukaan laut. Pembagian daerah penelitian menjadi beberapa satuan geomorfologi pada dasarnya adalah untuk memisahkan dan mengelompokkan kesamaan aspek pada suatu lahan yang memiliki karakteristik fisik tertentu. Dasar pemisahan dan penamaan satuan geomorfologi pada daerah pemetaan mengacu pada konsep dan klasifikasi berdasarkan sistem pemetaan geomorfologi ITC (Internasional Institute Aerospace and Earth Science) dalam Van Zuidam (1983). Aspek relief (morfologi) menunjukkan gambaran umum relief daerah yang terdiri dari aspek deskriptif seperti dataran dan perbukitan serta aspek morfometri yaitu berupa besar sudut lereng, ketinggian maupun kekasaran permukaan lahan serta bentuk asal yang menggambarkan asal-usul pembentukan dan perkembangan morfologi serta proses-proses yang bekerja.

\section{Kemiringan lereng}

Topografi Kabupaten Malang terdiri dari:

a. Kemiringan 0-2\% yang meliputi: kecamatan Bululawang, Gondanglegi, Tajinan, Turen, Kepanjen, Pagelaran dan Pakisaji.

b. Kemiringan 2-15\% yang meliputi: kecamatan Singosari, Lawang, Karangploso, Dau, Pakis, bampit, Sumberpucung, Kromengan, Pagak, Kalipare, Donomulyo, Bantur, Ngajum dan Gedangan.

c. Kemiringan $15-40 \%$ yang meliputi: kecamatan Sumbermanjing Wetan, Wagir, dan Wonosari).

d. Kemiringan 40\% meliputi: kecamatan Pujon, Ngantang, Kasembon, Poncokusumo, Jabung, Wajak, Ampelgading dan Tirtoyudo.

\section{Kondisi hidrologi}

Di bagian selatan Kabupaten Malang, air bawah tanah didapat pada batugamping Pegunungan selatan. Akibat dalamnya permuakaan air tanah dan permeabilitasnya yang terlokalisir, sumber-sumber air tersebut sangat sulit dimanfaatkan menggunakan sumur bor. Kabupaten Malang memiliki sumber mata air yang paling padat di Jawa Timur yakni sebanyak 684 sumber. Kebanyakan airnya dimanfaatkan untuk pengairan di dekat sumber atau mengalir ke saluran atau sungai menuju aliran dasar aliran utama sungai Brantas. 


\section{Kondisi klimatologi}

Kondisi iklim Kabupaten Malang menunjukan nilai kelembaban tertinggi adalah 90,74 \% yang jatuh pada bulan Desember, sedangkan nilai kelembaban terendah jatuh pada bulan Mei, rata-rata berkisar pada $87,47 \%$. Suhu rata-rata $26,1-28,3{ }^{\circ} \mathrm{C}$ dengan suhu maksimal 32,29 ${ }^{\circ} \mathrm{C}$ dan minimum $24,22{ }^{\circ} \mathrm{C}$. Rata-rata kecepatan angin di empat stasiun pengamat antara 1,8 sampai dengan 4,7 km/jam. Kecepatan angin terendah yakni berkisar pada 0,55 km/jam umumnya jatuh pada bulan November dan tertinggi yakni $2,16 \mathrm{~km} / \mathrm{jam}$ jatuh pada bulan September. Curah hujan rata-rata berkisar antara 1.800-3.000 $\mathrm{mm}$ per tahun, dengan hari hujan rata-rata antara $54-117$ hari/tahun.

\section{Variasi Temporal Laju Pelarutan Batugamping Mataair Sumber Agung}

Mataair Sumber Agung memiliki fluktuasi debit air pada saat musim penghujan maupun musim kemarau yang tidak terlalu besar. Aliran dari mataair ini termasuk aliran parennial (aliran sepanjang tahun). Kenaikan debit aliran yang tidak terlalu besar menunjukkan matatair Sumber Agung termasuk mataair yang memiliki tipe saluran diffuse atau fissure.

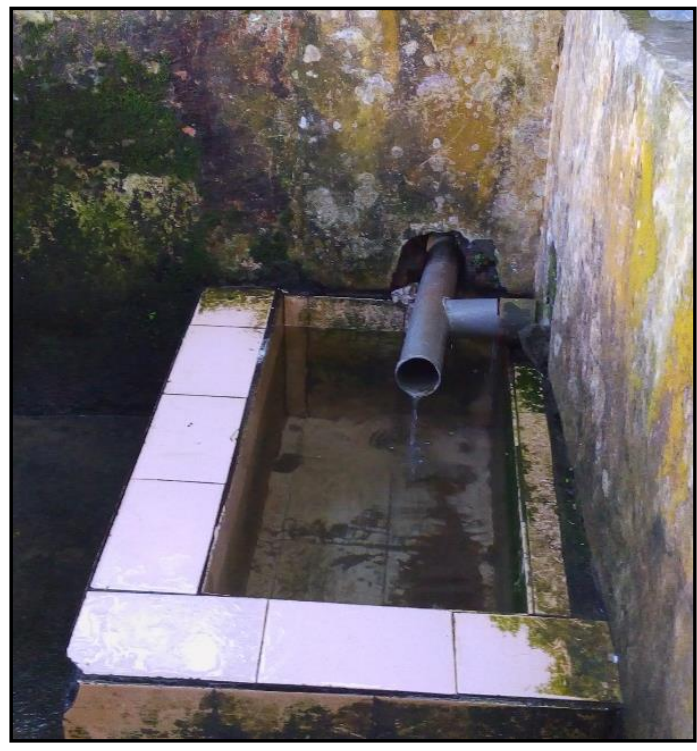

Gambar 3. Lokasi Mataair Sumber Agung (Sumber: Dokumentasi Penelitian, 2018)

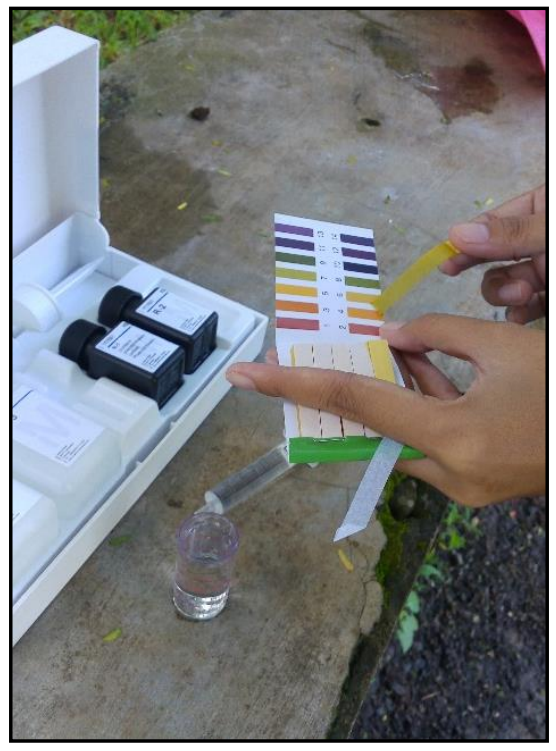

Gambar 4. Pengukuran pH pada mataair (Sumber: Dokumentasi Penelitian, 2018)

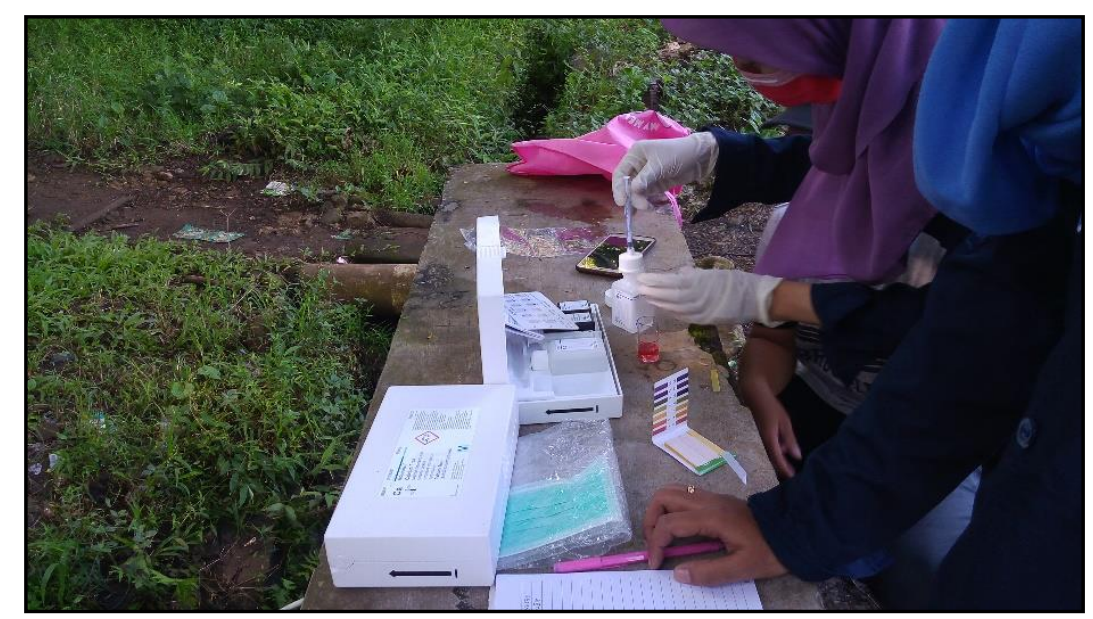

Gambar 5. Pengukuran $\mathrm{HCO}_{3}^{-}$dengan Alkalinity test kit 
Konsentrasi $\mathrm{HCO}_{3}{ }^{-}$mataair tahunan Sumber Agung dijelaskan pada Gambar 6 berikut.

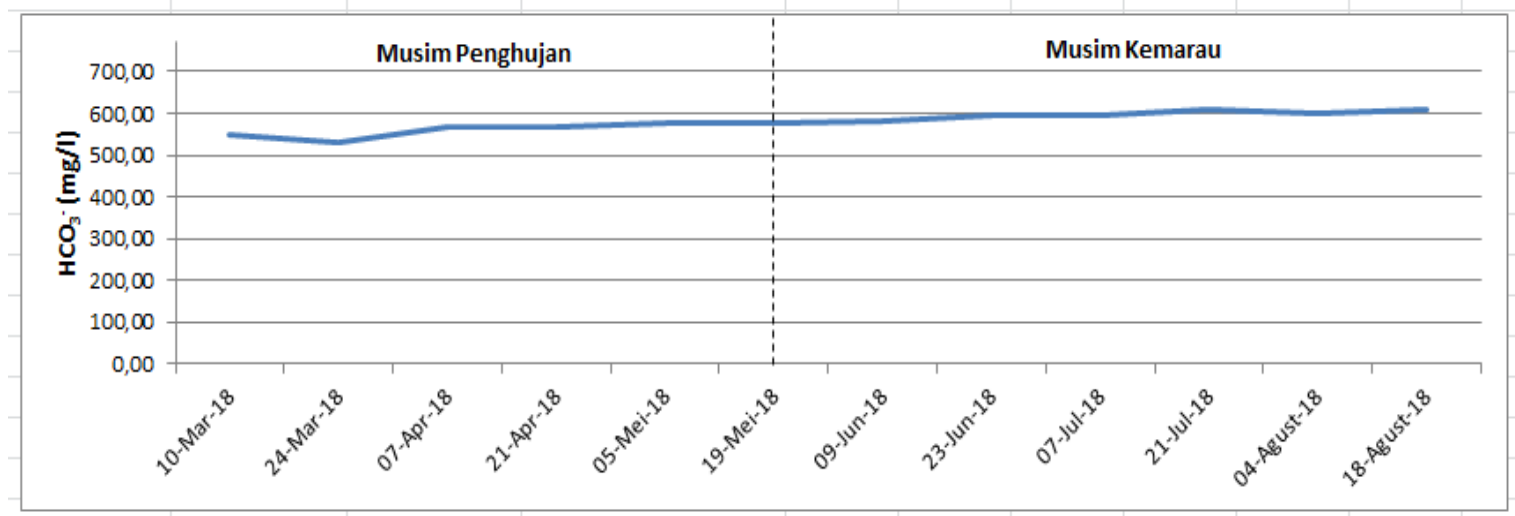

Gambar 6. Fluktuasi Konsentrasi $\mathrm{HCO}_{3}^{-}(\mathrm{mg} / \mathrm{l})$ pada Mataair Sumber Agung (Sumber: Analisis Data, 2018)

\section{Pembahasan}

Berdasarkan Gambar 6 dapat diketahui bahwa konsentrasi $\mathrm{HCO}_{3}^{-}$terlarut tahunan tertinggi yang terdapat pada mataair Sumber Agung terjadi pada saat musim kemarau, tepatnya pada tanggal 21 Juli 2018 sebesar 609,71 mg/l. Sedangkan konsentrasi $\mathrm{HCO}_{3}{ }^{-}$ terlarut tahunan terendah yang terdapat pada mataair Sumber Agung terjadi pada saat musim penghujan, tepatnya pada tanggal 24 Maret 2018 yakni sebesar 531,72 mg/l. Faktor penyusun batuan karbonat batugamping di daerah tangkapan mataair Sumber Agung masih tergolong masif, sehingga air masih sulit menembus rongga-rongga batuan. Keadaan ini menjadikan aliran air tanah mengalir cukup lambat dan membutuhkan waktu lebih lama untuk dapat sampai pada mataair. Proses ini menjadikan pelarutan batugamping cukup intensif dan berpotensi memiliki kandungan material terlarut yang tinggi.

Pada saat terjadinya hujan maka debit mataair terjadi peningkatan, hal tersebut menyebabkan terjadinya water rock interaction mengecil sehingga menyebabkan konsentrasi $\mathrm{HCO}_{3}{ }^{-}$terlarut pada air menurun karena air bersifat agresif. Secara teori naiknya debit mataair pada komponen conduit akan diikuti oleh naiknya gas karbondioksida. Oktama (2014) menjelaskan adanya hubungan antara fluktuasi debit dengan pola perubahan kandungan ion yaitu kalsium dan bikarbonat. Hasil uji scatter plot oleh Oktama (2014) antara debit dengan kandungan ion terlarut dominan terlarut menunjukkan keberadaan hubungan negatif yang memiliki arti jika debit mengalami penurunan, maka kandungan ion dominan terlarut akan semakin tinggi.

Besarnya pelarutan di suatu kawasan karst dipengaruhi oleh besarnya curah hujan, kemurnian batuan karbonat, dan konsentrasi $\mathrm{CO}_{2}$. Seperti yang diketahui bahwa laju pelarutan akan berbanding lurus dengan nilai runoff dan konsentrasi $\mathrm{HCO}_{3}$ - Pada saat terjadinya hujan maka debit mataair akan meningkat dan menyebabkan peluang water rock interaction mengecil sehingga menyebabkan konsentrasi $\mathrm{HCO}_{3}{ }^{-}$terlarut pada air menurun karena air bersifat agresif. Secara teori naiknya debit mataair pada komponen conduit akan diikuti oleh naiknya gas karbondioksida.

Air hujan yang jatuh ke permukaan bumi tidak semuanya langsung masuk terserap oleh tanah atau menjadi limpasan permukaan. Sebagian dari air hujan tersebut mengalami evaporasi yaitu proses air menjadi uap, transpirasi yaitu perubahan air menjadi uap melalui metabolisme tanaman, inkorporasi yaitu pemindahan air menjadi struktur fisik vegetasi pada proses pertumbuhan, dan sublimasi yaitu air yang berubah wujud secara langsung dari wujud padat menjadi gas (Eagleson, 1970 dalam seyhan, 1990). 


\section{Kesimpulan}

Berdasarkan hasil pengamatan dan analisis yang telah dibahas, maka dapat ditarik kesimpulan, Konsentrasi $\mathrm{HCO}_{3}^{-}$terlarut tahunan tertinggi yang terdapat pada mataair Sumber Agung terjadi pada saat musim kemarau, sebesar 609,71 mg/l. Sedangkan konsentrasi $\mathrm{HCO}_{3}^{-}$terlarut tahunan terendah yang terdapat pada mataair Sumber Agung terjadi pada saat musim penghujan, yakni sebesar 531,72 mg/l.

Berdasarkan kesimpulan tersebut disarankan perlu meningkatan kualitas sumberdaya manusia. Peningkatan sumberdaya manusia penduduk yang menetap dikawasan Karst dimaksudkan untuk meningkatkan kesadaran pengelolaan lingkungan yang baik. Peningkatan sumberdaya manusia di antaranya dengan melakukan pelatihan pengelolaan lingkungan Karst.

\section{Ucapan Terimakasih}

Penulisan hasil penelitian ini tidak lepas dari bantuan berbagai pihak secara langsung maupun tidak langsung. Oleh karena itu kami berterimakasih kepada LPPM Universitas Kanjuruhan Malang yang telah membantu dalam proses pelaksanaan penelitian, DPRM Kemenristekdikti yang telah memberikan bantuan dana untuk melaksanakan Penelitian, Randhiki Gusti Perdana yang telah membantu pelaksanaan penelitian, Badan Informasi Geospasial (BIG), Badan Pusat Statistik (BPS), Badan Meteorologi Klimatologi dan Geofisika (BMKG) atas kontribusinya dalam proses pengumpulan data.

\section{Daftar Rujukan}

Cvijik., 2006. Types Morphology the Terrains Characteristics. Acade'mie des Sciences. Paris.

Kresic, N. dan Stevanovic, Z., 2010. "Groundwater Hydrology of Springs.Engineering, theory, management, and sustainability". Elsevier Inc.,USA. (3):91-104.

Seyhan, E. 1990. Dasar-dasar Hidrologi (terjemahan Fundamental of Hydrology oleh Sentot Subagya). Gadjah Mada University Press: Yogyakarta

Suyono. 2004. Presipitasi, Evaporasi dan Hidrologi Dasar. Universitas Gadjah Mada dengan Yayasan 